\title{
Is testis-sparing surgery safe in small testicular masses? Results of a multicentre study
}

\author{
Murat Keske, MD; ${ }^{1}$ Abdullah Erdem Canda, MD, ;,2 Serdar Yalcin, MD; ${ }^{; 3}$ Aydan Kilicarslan, MD; \\ Yusuf Kibar, MD, Can Tuygun, MD, Evrim Onder, MD,4 Ali Fuat Atmaca, MD,1,2 Asif Yildirim, MD, \\ Sidika Seyma Ozkanli, MD; ${ }^{5}$ Olcay Kandemir, MD; Taner Kargi, MD; Mehmet Sar, MD; ${ }_{;}^{7}$ Volkan Tugcu, MD; \\ Berkan Resorlu, MD; Yilmaz Aslan, MD; Selcuk Sarikaya, MD; ${ }^{9}$ Ugur Boylu, MD;10 Ali Fuat Cicek, MD; \\ Halil Basar, MD; ${ }^{6}$ Altug Tuncel, MD,; Mevlana Derya Balbay, MD ${ }^{11}$
}

'Ankara Ataturk Training and Research Hospital, Ankara, Turkey; ${ }^{2}$ Ankara Yildirim Beyazit University, School of Medicine, Ankara, Turkey; ${ }^{3}$ Gulhane Military Medical Academy, Ankara, Turkey; ${ }^{4}$ Diskapi Yildirim Beyazit Training and Research Hospital, Ankara, Turkey; ${ }^{5}$ Medeniyet University, Goztepe Training and Research Hospital, Istanbul, Turkey; ${ }^{6}$ Dr. Abdurrahman Yurtaslan Ankara Oncology Training and Research Hospital, Ankara, Turkey; ${ }^{7}$ Bakirkoy Dr. Sadi Konuk Training and Research Hospital, Istanbul, Turkey; ${ }^{8}$ Numune Training and Research Hospital, Ankara, Turkey; ${ }^{9}$ Kecioren Training and Research Hospital, Ankara, Turkey; ${ }^{10}$ Umraniye Training and Research Hospital, Istanbul, Turkey; ${ }^{11}$ Memorial Sisli Hospital, Istanbul, Turkey

Cite as: Can Urol Assoc J 2017;11 (3-4):E100-4. http://dx.doi.org/10.5489/cuaj.4016 Published online March 16, 2017

\section{Abstract}

Introduction: Our goal was to evaluate benign and malignant lesions and testicular intraepithelial neoplasia (TIN) in the neighbouring normal-appearing testis tissue in men who underwent radical orchiectomy for testicular mass with a pathologic tumour size of $\leq 3 \mathrm{~cm}$. Methods: In this retrospective, multicentre study, data of 252 patients from 11 different institutions were included. Patients were divided into three groups based on tumour size: Group $1(0-1 \mathrm{~cm} ; \mathrm{n}=35)$, Group $2(1.1-2 \mathrm{~cm} ; \mathrm{n}=99)$, and Group 3 (2.1-3 cm; $n=118)$. Benign lesions and TIN were sought in the neighbouring testicular tissue and compared between groups. Results: Mean patient age was 32.3 years. Benign lesions were reported in $54.3 \%, 33.3 \%$, and $14.4 \%$ of Groups 1, 2, and 3, respectively ( $p<0.05$ between groups). TIN was detected in $20 \%$, $42.4 \%$, and $41.5 \%$ of Groups 1,2 , and 3, respectively $(p<0.05$ for Group 1 vs. Groups 2 and 3; p>0.05 for Groups 2 vs. 3). Multifocality was detected in $8.6 \%, 4 \%$, and $0 \%$ of Groups 1 , 2 , and 3 , respectively $(\mathrm{p}<0.05$ for both Group 1 vs. Group3 and for Group 2 vs. Group 3; p $>0.05$ for Group 1vs. Group 2). A tumour cutoff size of $1.5 \mathrm{~cm}$ was found to be significant for detecting benign tumour. TIN and multifocality rates were similar in patients with a tumour size of $\leq 1.5 \mathrm{vs}$. $>1.5 \mathrm{~cm}(\mathrm{p}>0.05)$. Conclusions: Benign lesions and TIN in the neighbouring testis were significantly decreased and multifocality was increased in patients with a tumour mass size of $\leq 1 \mathrm{~cm}$. Testis-sparing surgery should be performed with caution and a safety rim of normal tissue should also be excised.

\section{Introduction}

Testicular cancer constitutes $1-1.5 \%$ of the male neoplasms and $5 \%$ of urological tumours. ${ }^{1-3}$ Although standard therapy for testicular cancer is radical inguinal orchiectomy, in patients with bilateral tumours or tumour in a solitary testis, orchiectomy will lead to infertility and hormonal deficiency. Therefore, in this patient group, organ-sparing surgery has been suggested as an option when the tumour volume is $<30 \%$ of the testicular volume, applying surgical principles. ${ }^{4}$

We carried out this multicenter study to investigate if testis-sparing surgery (TSS) could be performed in small testicular masses.

\section{Methods}

In this retrospective and multicentre study, data of patients from 11 different institutions who underwent radical inguinal orchiectomy $(n=252)$ for testicular mass with a macroscopic tumour size of $3 \mathrm{~cm}$ or less were included. Ethical approval was obtained.

Because the number of patients with a testicular mass size of $<3 \mathrm{~cm}$ and especially $<1 \mathrm{~cm}$ is very limited in almost every institution, we decided to carry out a multi-institutional study and reviewed pathology reports to classify according to the tumour size, histopathology (benign or malignant), multifocality, and presence of concomitant testicular intraepithelial neoplasia (TIN) in the non-tumoural testicular tissue when the primary tumour is malignant.

Patients were divided into three groups based on pathological tumour size: Group $1(0-1 \mathrm{~cm} ; \mathrm{n}=35)$, Group 2 (1.1-2 cm; $n=99)$, and Group 3 (2.1-3 cm; n=118). Groups were compared in terms of tumour pathology (benign or malignant), presence of TIN, and multifocality in the neigh- 
bouring, normal-appearing non-tumoural testicular tissue. Patients were further divided into two groups (Group A and B) based on tumour size of $\leq 1.5 \mathrm{~cm}$ and $1.6-3 \mathrm{~cm}$.

Pathological evaluation

\section{Macroscopical sampling}

Orchiectomy materials were left in $10 \%$ buffered formaldehyde solution for 12-24 hours in order to get optimal tissue fixation. Then the pathological sampling was done according to the international guidelines and included the sampling from spermatic cord surgical margin, rete, and epdidymis. In each material, the testicular paranchyme was cut in $5 \mathrm{~mm}$ thick sections to detect any tumoural mass or non-tumoural lesion and the diameters of lesional areas were measured. Any lesional area was sampled with the peripheral non-lesional paranchyme and the peripheral membranes, including the tunica albuginea. In partial orchiectomies, the excision line was also sampled as a surgical margin.

\section{Microscopical examination}

After an overnight tissue followup procedure, the sampled tissues were embedded in paraffin blocks and sectioned to obtain 4-5 $\mu \mathrm{m}$ tissue slides. The slides were stained with hematoxylene and eosin stain and examined under light microscope.

\section{Frozen section examination}

Frozen examinations were done in fresh tissues without formaldehyde fixation and sectioning was carried out in a frozen machine. After the rapid hematoxylene and eosin staining, the frozen slides were examined under light microscope.

\section{Statistical analysis}

Statistical analyses were done using IBM ${ }^{\circledR}$ SPSS $^{\circledR}$ Statistics Version 22 and MedCalc ${ }^{\circledR}$ V.11.4.2.0 programs. Qualitative data were tested using Pearson $\chi^{2}$, Yates $\chi^{2}$ veya Fisher's $\chi^{2}$ tests. Receiver operating characteristic (ROC) analysis was done in order to identify cutoff values. Statistical significance was considered as $\mathrm{p}<0.05$.

\section{Results}

Mean patient age was $32.3 \pm 11.9$ years (range $1-79$ ). Mean patient age in Groups 1, 2, and 3 were 30.7, 30.9, and 34.3 years, respectively. Mean tumour size was $2.0 \pm 0.8 \mathrm{~cm}$ (range 0.3-3).

Benign lesions that were histopathologically diagnosed included mature teratoma, adenomatoid tumour, granulomatous orchitis, chronic orchitis, epididim-orchitis, epididymal cyst, Leydig cell tumour, Sertoli cell tumour, fibrous pseudotumour, tunica albugenia cyst, epidermal cyst, leiomyoma, fibroma, juvenile granulosa cell tumour, granulomatous epididymitis, and microlithiasis with epididymal abscess. Malignant lesions that were diagnosed histopathologically included seminoma classical type, anaplastic seminoma, yolc sac tumour, malignant lymphoma, leiomyosarcoma, embryonal carcinoma, teratocarcinoma, mixed malignant germ cell tumour, and malignant epithelioid mesothelioma.

Comparison of the groups in terms of testicular mass pathology (benign vs. malignant), presence of TIN, and multifocality in the non-tumoural neighbouring testis tissue are summarized in Table 1 and Fig. 1. A tumour cutoff size of 1.5 $\mathrm{cm}$ was found to be significant for detecting benign histology of the mass. Comparison of the groups due to a tumour cutoff size of $1.5 \mathrm{~cm}$ in terms of testicular mass pathology (benign vs. malignant), presence of TIN, and multifocality in the non-tumoural neighbouring testis tissue are summarized in Table 2 and Fig. 2.

Overall, there were seven patients with multifocal tumours in the testis. Of those, seminoma (classical type), embryonal carcinoma, and teratocarcinoma were reported in five, one, and one patient, respectivei y. Distance between the multifocal tumours varied from $0.2-1 \mathrm{~cm}$ measured microscopically.

\begin{tabular}{|c|c|c|c|c|c|}
\hline & \multicolumn{3}{|c|}{ Testis mass pathology } & \multirow{2}{*}{$\begin{array}{c}\text { Non-tumoural testis tissue } \\
\text { TIN }\end{array}$} & \multirow{2}{*}{$\begin{array}{c}\text { Non-tumoural testis tissue } \\
\text { Multifocality }\end{array}$} \\
\hline & Tumour size & Benign & Malignant & & \\
\hline Group 1 ( $n=35)$ & $\leq 1 \mathrm{~cm}$ & $19(54.3 \%)$ & $16(45.7 \%)$ & $7(20.0 \%)$ & $3(8.6 \%)$ \\
\hline Group 2 (n=99) & $1.1-2.0 \mathrm{~cm}$ & $33(33.3 \%)$ & $66(66.7 \%)$ & $42(42.4 \%)$ & $4(4.0 \%)$ \\
\hline Group 3 ( $n=118)$ & $2.1-3.0 \mathrm{~cm}$ & $17(14.4 \%)$ & $101(85.6 \%)$ & 49 (41.5\%) & $0(0.0 \%)$ \\
\hline $\mathrm{p}$ & & $\begin{array}{r}\text { Group } \\
\mathrm{p}= \\
\text { Group } \\
\mathrm{p}= \\
\text { Group } \\
\mathrm{p}=\end{array}$ & $\begin{array}{l}\text { oup2 } \\
\text { oup3 } \\
\text { oup3 } \\
\text { oun }\end{array}$ & $\begin{array}{c}\text { Group1-Group2 } \\
p=0.031^{*} \\
\text { Group1-Group3 } \\
p=0.034^{*} \\
\text { Group2-Group3 } \\
p=0.894\end{array}$ & $\begin{array}{c}\text { Group1-Group2 } \\
p=0.337 \\
\text { Group1-Group3 } \\
p=0.011^{*} \\
\text { Group2-Group3 } \\
p=0.042^{*}\end{array}$ \\
\hline
\end{tabular}




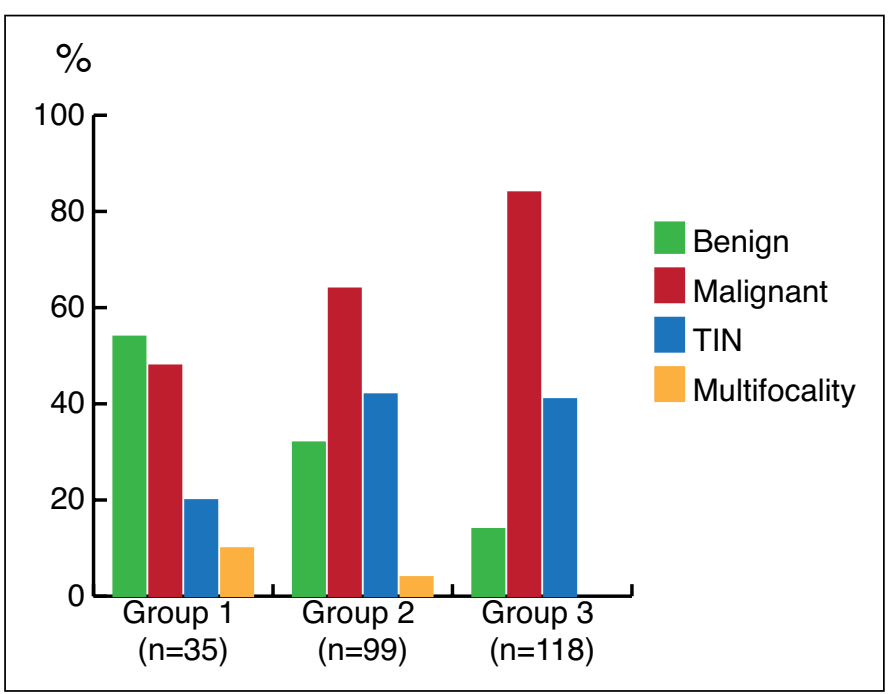

Fig. 1. Percentage of benign and malignant testicular tumours, testicular intraepithelial neoplasia (TIN) and multifocality in the neighbouring testis tissue (Group 1: tumour size $\leq 1 \mathrm{~cm}$; Group 2: tumour size 1.1-2.0 cm; Group 3: tumour size $2.1-3.0 \mathrm{~cm}$ ). $P$ values for detecting benign and malignant testicular mass lesions between groups include Group 1 vs. Group 2, $p=0.047$; Group 1 vs. Group 3, $p=0.000$; and Group 2 vs. Group 3, $p=0.002$. P values for detecting TIN between groups include Group 1 vs. Group 2, $p=0.031$; Group 1 vs. Group 3, $\mathrm{p}=0.034$; and Group 2 vs. Group 3, $\mathrm{p}=0.894$. P values for detecting multifocality between groups include Group 1 vs. Group 2, p=0.337; Group 1 vs. Group 3, $\mathrm{p}=0.011$; and Group 2 vs. Group3, $\mathrm{p}=0.042$.

\section{Discussion}

The European Association of Urology (EAU) guidelines have stated that although organ-sparing surgery is not indicated in the presence of non-tumoural contralateral testis, it can be attempted in special cases, with all the necessary precautions. ${ }^{5}$ Synchronous bilateral testicular tumours, metachronous contralateral tumours, or a tumour in a solitary testis with normal preoperative testosterone levels have been included as indications for TSS when tumour volume is less than $30 \%$ of the testicular volume and surgical rules are respected. ${ }^{5}$ Presence of TIN has always been a concern in performing TSS and the rate of associated TIN was reported to be high at up to $82 \%{ }^{5}$ However, this very high percent of TIN was reported to be detected in the overall testis tumour group, including both small-sized and larger-sized testis tumours.

To date, very few studies have investigated the presence of TIN and multifocality rates in the neighbouring, normal-

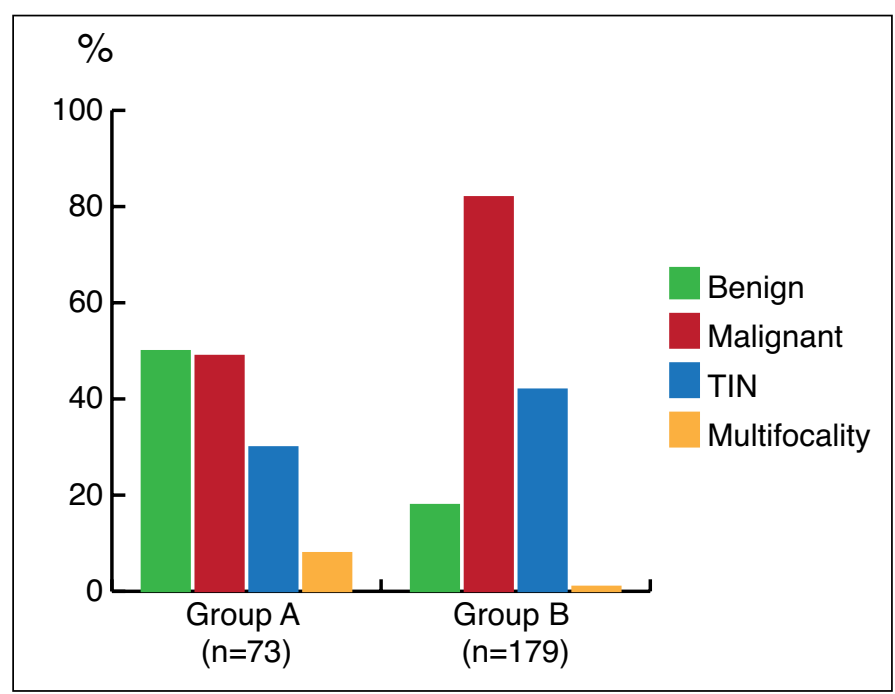

Fig. 2. Percentage of benign, malignant testicular tumours, testicular intraepithelial neoplasia (TIN) and multifocality in the neighbouring testis tissue due to a tumour cutoff size of $1.5 \mathrm{~cm}$ (Group A: tumor size $\leq 1.5 \mathrm{~cm}$; Group B: tumour size $1.6-3.0 \mathrm{~cm}$ ). $P$ values for detecting benign and malignant testicular mass lesions between groups include Group $A$ vs. Group $B, p=0.000$. $P$ values for detecting TIN between groups include Group $A$ vs. Group $B, p=0.069$. $P$ values for detecting multifocality between groups include Group $A$ vs. Group $B, p=0.012$.

appearing testis tissue and diagnosing benign lesions in the testicular mass lesions in relation to tumour size. Favilla et al very recently investigated the prevalence of TIN and multifocality in testis tumours $\leq 2 \mathrm{~cm}$ in size. ${ }^{6}$ Similar to our study, they evaluated their patients due to testis tumour size including (Group: 1 0-1 cm, $\mathrm{n}=76$; Group 2: $1.1-2 \mathrm{~cm}$, $\mathrm{n}=22$; Group 3: $2.1-3 \mathrm{~cm}, \mathrm{n}=26) .{ }^{6}$ In their study, TIN was identified in $0 \%, 7.9 \%$, and $4.7 \%$ of each group, respectively. ${ }^{6}$ Patients with a tumour size of $\leq 1 \mathrm{~cm}$ had significantly decreased percentage of TIN compared to patients with a tumour size of $1.1-2 \mathrm{~cm}$ or $>2 \mathrm{~cm}(\mathrm{p}<0.05) .{ }^{6}$ Interestingly, they did not detect any TIN in patients with a tumour size of $\leq 1 \mathrm{~cm}$, which might be explained by the limited number of patients (six) in that particular group.

Similar to Favilla et al, we detected that percentage of TIN was significantly decreased as the tumour size decreased (Table 1). In addition, in our multicentre study 35, 99, and 188 patients, respectively, were included in each particular group. However, TIN was detected in $20 \%$ of the patients $(n=35)$ with a tumour size of $\leq 1 \mathrm{~cm}$.

\begin{tabular}{|c|c|c|c|c|c|}
\hline & & Testis ma & ss pathology & Non-tumoural testis tissue & Non-tumoural testis tissue \\
\hline & Testicular mass size & Benign lesions & Malignant lesions & TIN & Multifocality \\
\hline Group A (n=73) & $\leq 1.5 \mathrm{~cm}$ & $37(50.7 \%)$ & $36(49.3 \%)$ & $22(30.1 \%)$ & $5(6.8 \%)$ \\
\hline Group B $(n=179)$ & $1.6-3.0 \mathrm{~cm}$ & $32(17.9 \%)$ & 147 (82.1\%) & $76(42.4 \%)$ & $2(1.1 \%)$ \\
\hline $\mathrm{p}$ & & \multicolumn{2}{|c|}{$\begin{array}{c}\text { Group A-Group B } \\
\mathrm{p}=0.000^{*}\end{array}$} & $\begin{array}{c}\text { Group A-Group B } \\
\mathrm{p}=0.069\end{array}$ & $\begin{array}{l}\text { Group A-Group B } \\
\qquad p=0.012^{*}\end{array}$ \\
\hline
\end{tabular}


Tumour multifocality is another concern related with TSS. Favilla et al reported multifocality occurring at a rate of $1.6 \%, 7.1 \%$, and $7.1 \%$, respectively in their study groups. ${ }^{6}$ However, in contrast to their study, we detected multifocality at a rate of $8.6 \%, 4 \%$, and $0 \%$, respectively, in our three study groups. This discrepancy may be a result of paucity in patients with small masses $(<1 \mathrm{~cm})$ in their study. However, based on our findings, multifocality rates decreased as the tumour size increased (Tables 1 and 2).

Gentile et al reported the outcomes of TSS they performed in patients with small testicular masses $(<25 \mathrm{~mm}$ in diameter). ${ }^{7}$ At final pathological analysis, six patients $(40 \%)$ were found not to have tumours, another seven patients $(46.7 \%)$ had benign neoplasms, and malignant tumour was found in only two patients (13.3\%). Other studies have also reported $75-80 \%$ of benign conditions in small, nonpalpable tumours. ${ }^{8-10}$ Various published studies also suggest that small and non-palpable lesions smaller than $2 \mathrm{~cm}$ in size are benign lesions. ${ }^{10-12}$ Giannarini et al stated that TSS with frozen section examination may be considered a viable option for patients with non-palpable, small tumours with the advantage of sparing an unnecessary radical orchiectomy in the presence of healthy contralateral testes. ${ }^{10}$

In the published literature, some authors defined small testis tumours as $<2 \mathrm{~cm}$ in diameter, ${ }^{4,11,12}$ whereas others defined them as $<2.5 \mathrm{~cm}$ and non-palpable, ${ }^{7,13}$ although no particular reason was stated as to why these particular tumour size definitions were used. In our study, we identified a tumour cutoff size of $1.5 \mathrm{~cm}$ as significant for detecting benign tumour in the testis, although in the neighbouring testis tissue, no significant difference was detected in terms of TIN in patients with a tumour size of $\leq 1.5 \mathrm{~cm}$ or $>1 \mathrm{~cm}(p=0.069)$ (Table 2). Therefore, a tumour size of $<1.5 \mathrm{~cm}$ might be used for small testicular tumours and $<1 \mathrm{~cm}$ for very small testicular tumours.

Our study has some limitations. Firstly, the numbers of patients included in each group is limited. Secondly, certain parameters, including followup of patients and preoperative serum tumour markers are missing due to the multicentre nature of the study. Knowing preoperative serum tumour markers could have been important in order to predict a benign tumour in a patient with normal serum tumour markers and a tumour size of $<1.5 \mathrm{~cm}$.

In patients with $\leq 1 \mathrm{~cm}$ testicular tumour size, one of every two had a benign pathology, and among those with malignant lesions, only one of every five patients had TIN in the normal-appearing, neighbouring testis. Therefore, patients in this particular group might be suitable for TSS with intraoperative tumour bed frozen biopsies, especially if they have normal preoperative serum tumour markers, or in carefully selected cases with synchronous bilateral testicular tumours metachronous contralateral tumours, or a tumour in a solitary testis with normal preoperative testosterone levels. Patients with TIN will need to be treated with adjuvant radiotherapy to the testis in the postoperative period. TSS in small testicular masses is expected to have the advantages of preserving residual testicular function and fertility, with additional benefits on patient psychology.

Presence of multifocality should always be a concern in performing TSS. Among the patients with multifocal tumours $(n=7)$, distance between multifocal tumours was found to be $0.2-1 \mathrm{~cm}$ in our study. Therefore, we suggest excision of at least $1 \mathrm{~cm}$ of normal testis tissue with the tumour when TSS is performed.

\section{Conclusion}

In conclusion, our study demonstrated that benign lesions and TIN in the neighbouring testis were significantly decreased and multifocality was increased in patients with a tumour mass size of $1 \mathrm{~cm}$ or less. This paradox imposes a unique risk of leaving malignant satellite lesions when considering TSS. Therefore, when TSS is contemplated, a $1 \mathrm{~cm}$ safety rim of normal testicular tissue should be excised together with the main mass. Further studies with higher numbers of patients are required.

Competing interests: The authors report no competing personal or financial interests.

This paper has been peer-reviewed.

\section{References}

1. La Vecchia C, Bosetti C, Lucchini F, et al. Cancer mortality in Europe, 2000-2004, and an overview of trends since 1975. Ann Oncol 2010;21:1323-60. https://doi.org/10.1093/annonc/mdp530

2. Engholm G, Ferlay J, Christensen N, et al. NORDCAN—a Nordic tool for cancer information, planning, quality control, and research. Acta Oncol 2010;49:725-36. https://doi.org/10.3109/02841861003782017

3. Klatte $\mathrm{T}$, de Martino M, Arensmeier $\mathrm{K}$, et al. Management and outcome of bilateral testicular germ cell tumours: A 25-year, single-centre experience. Int I Urol 2008;15:821-6. https://doi.org/10.1111/ j.1442-2042.2008.02107.x

4. Heidenreich A, Weissbach L, Hölt W, et al. German Testicular Cancer Study Group. Organ-sparing surgery for malignant germ cell tumour of the testis. J Urol 2001;166:2161-5. https://doi.org/10.1016/ S0022-5347(05)65526-7

5. Albers P, Albrecht W, Algaba F, et al. Guidelines on testicular cancer: 2015 update. Eur Urol 2015;68:105468. https://doi.org/10.1016/i.eururo.2015.07.044

6. Favilla V, Russo GI, Spitaleri F, et al. Prevalence of intratubular germ cell neoplasia and multifocality in testicular germ cell tumours $\leq 2 \mathrm{~cm}$ : Relationship with other pathological features. Clin Genitourin Cancer 2015;13:e31-5. htrps://doi.org/10.1016/i.clgc.2014.06.009

7. Gentile G, Brunocilla E, Franceschelli A, et al. Can testis-sparing surgery for small testicular masses be considered a valid alternative to radical orchiectomy? A prospective, single-centre study. Clin Genitourin Cancer 2013;11:522-6. https://doi.org/10.1016/i.llgc.2013.04.033

8. Carmignani L, Gadda F, Gazzano $G$, et al. High incidence of benign testicular neoplasms diagnosed by ultrasound. J Urol 2003;170:1783-6. https://doi.org/10.1097/01.ju.0000092066.01699.90

9. Carmignani L, Gadda F, Mancini M, et al. Detection of testicular ultrasonographic lesions in severe male infertility. J Urol 2004;172:1045-7. htrps://doi.org/10.1097/01.ju.0000134892.10525.39

10. Giannarini $G$, Dieckmann KP, Albers $P$, et al. Organ-sparing surgery for adult testicular tumours: A systematic review of the literature. Eur Urol 2010;57:780-90. https://doi.org/10.1016/i.eururo.2010.01.014

11. Connolly SS, D’Arcy FT, Bredin HC, et al. Value of frozen section analysis with suspected testicular malignancy. Urology 2006;67:162-5. https://doi.org/10.1016/i.urology.2005.07.041 
Keske et al.

12. Carmignani L, Morabito A, Gadda F, et al. Prognostic parameters in adult impalpable ultrasonographic lesions of the testicle. J Urol 2005;174:1035-8. https://doi.org/10.1097/01.ju.0000170236.01 129.d4

13. Steiner $\mathrm{H}$, Höltt L, Maneschg $\mathrm{C}$, et al. Frozen section analysis-guided organ-sparing approach in testicular tumours: Technique, feasibility, and long-term results. Urology 2003;62:508-13. https://doi.org/10.1016/S0090-4295(03)00465-5

Correspondence: Dr. Murat Keske, Ankara Ataturk Training and Research Hospital, Ankara, Turkey; muratkeske@yahoo.co.uk 